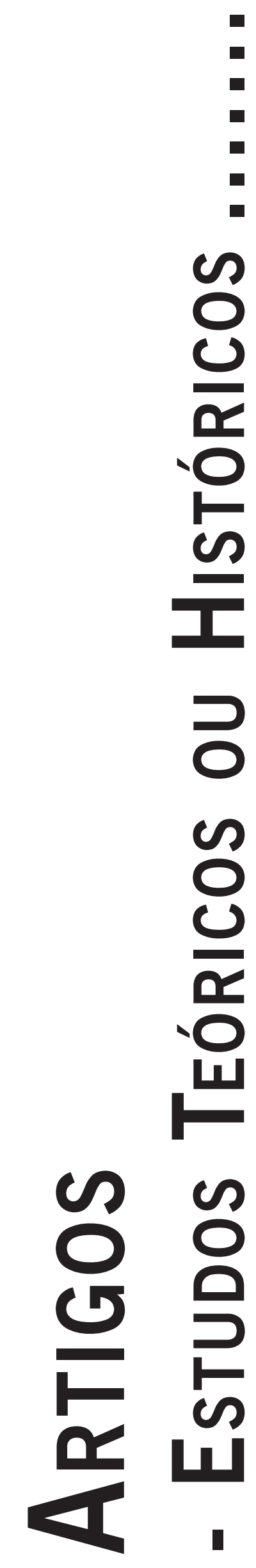




\title{
ELEMENTOS PARA UMA HISTÓRIA DA PSICOTERAPIA DE GRUPO ${ }^{1}$
}

\author{
Elements for a History of Group Psychotherapy
}

Elementos para una Historia de la Psicoterapia de Grupo

Georges Daniel Janja Bloc Boris

\begin{abstract}
Resumo: O texto discute a história da psicoterapia de grupo, destacando suas transformações até o surgimento dos grupos gestálticos. A história da psicoterapia de grupo revela sua evolução sócio-pedagógica. As primeiras propostas, eminentemente didáticas, exortativas e repressivas, foram seguidas pela inclusão da psicanalíse, permitindo a ampliação do enfoque sobre o indivíduo para uma perspectiva interpessoal, que enfatizava o grupo como uma "família". O texto destaca o advento das propostas de Moreno, Adler, Burrow, Bierer, Lewin e Rogers, que criaram um vasto campo de atuação entre as psicoterapias humanistas, caracterizadas como "pedagogias da vida", voltadas aos recursos disponíveis nos grupos. É neste contexto que podemos incluir a gestalt-terapia, apesar de alguns limites quanto às suas iniciativas grupais, pelo menos na prática de seu criador, Frederick Perls, e de alguns de seus seguidores. Para além de sua formação psicanalítica, Perls incorporou, a partir de sua própria experiência, uma série de influências, que vão desde o teatro expressionista ao zen-budismo, passando pela análise do caráter, o psicodrama, até a fenomenologia e o existencialismo. Perls, que se considerava um psicanalista medíocre, criou uma abordagem viva, que, hoje, integra o rol dos referenciais psicológicos mais reconhecidos, particularmente no que se refere às práticas grupais.
\end{abstract}

Palavras-chave: História da psicologia; Psicoterapia de grupo; Gestalt-Terapia; Grupos gestálticos.

Abstract: The paper discusses the history of group psychotherapy, highlighting its transformations until the emergence of the gestaltic groups. The history of group psychotherapy reveals its socio-pedagogical evolution. The first proposals, eminently didactic, exhortative and repressive, were followed by the inclusion of psychoanalysis, allowing the expansion from the focus on the individual to an interpersonal perspective, which had emphasized the group as a "family". The text highlights the advent of the proposals of Moreno, Adler, Burrow, Bierer, Lewin and Rogers, who have created a vast field of action between the humanistic psychotherapies, characterized as "pedagogies of life", focused on the available resources in groups. It is in this last context that we can include the gestalt therapy, although some limits on their group initiatives, at least in the practice of its founder, Frederick Perls, and some of his followers. Beyond his psychoanalytic training, Perls had incorporated, from his own experience, a number of influences, ranging from expressionist theatre to zen buddhism, character analysis, psychodrama, until phenomenology and existentialism. Perls, who considered himself a mediocre psychoanalyst, have created a living approach, which integrates the list of the more recognized psychological references, particularly with regard to group practices.

Keywords: History of psychology; Group psychotherapy; Gestalt-Therapy; Gestaltic groups.

Resumen: El artículo analiza la historia de la psicoterapia de grupo, destacando sus transformaciones hasta la aparición de los grupos gestálticos. La historia de la psicoterapia de grupo revela su evolución socio-pedagógica. Las primeras propuestas, eminentemente didácticas, exhortativas y represivas, fueron seguidas por la inclusión del psicoanálisis, permitiendo la expansión del foco en el individuo a una perspectiva interpersonal, que enfatizó el grupo como una "familia". El texto destaca la llegada de las propuestas de Moreno, Adler, Burrow, Bierer, Lewin y Rogers, que crearan un vasto campo de acción entre las psicoterapias humanistas, caracterizadas como "pedagogías de la vida", centradas en los recursos disponibles en grupos. Es en este último contexto que podemos incluir la terapia gestáltica, aunque algunos límites en sus iniciativas de grupo, al menos en la práctica de su creador, Frederick Perls, y algunos de sus seguidores. De formación psicoanalítica, Perls hay incorporado, desde su propia experiencia, una serie de influencias, que van desde el teatro expresionista al budismo zen, el análisis del carácter, el psicodrama, hasta la fenomenología y el existencialismo. Perls, que se consideraba un psicoanalista mediocre, creó un enfoque vívido, que integra el rol de referenciales psicológicos más reconocidos, particularmente con respecto a las prácticas de grupo.

Palabras clave: Historia de la psicología; Psicoterapia de grupo; Terapia gestáltica; Grupos Gestálticos.

\footnotetext{
${ }^{1}$ Apresentado no III Congresso Sul-Brasileiro de Fenomenologia \& I Congresso Brasileiro de Psicologia \& Fenomenologia, realizado na Universidade Federal do Paraná (UFPR), entre os dias 12 e 14 de agosto de 2013.
} 
(...) A aprendizagem no sentido que se aplica aqui, isto é, aprendizagem vital, pressupõe uma mudança de atitude a respeito da pessoa inteira. Quando usada neste sentido, parece não haver diferença nítida entre a aprendizagem e os processos terapêuticos (Foulkes, 1976).

A teorização sobre os grupos vivenciais tem sido muito limitada e escassa, ainda que hajam contribuições significativas. Mesmo da parte daqueles que os propuseram originalmente, na forma que eles têm tomado na Psicologia Humanista. Acreditamos mesmo que estes que elaboraram o modelo original - no que pese a riqueza desse modelo - nunca conseguiram dizer satisfatoriamente as linhas gerais daquilo que têm intuído (Fonseca, 1988).

\section{Introdução}

Deixando de lado o teatro grego e algumas manifestações primitivas (como as curas em santuários, os rituais de feitiçaria, o curandeirismo e as romarias, por exemplo), parece haver amplo reconhecimento de que o médico Joseph Henry Pratt, em Boston (EUA), foi o iniciador do quê viria a ser caracterizada, posteriormente, como psicoterapia de grupo, no ano de 1905. Pratt organizou grupos de vinte a trinta pacientes tuberculosos, que se reuniam uma ou duas vezes por semana (Kadis, Krasner, Winick \& Foulkes,1976; Rattner, 1977; Kaplan \& Sadock, 1983). Tratava seus pacientes como alunos, lendo para eles acerca da doença e do método de cura e os apoiava quanto ao prognóstico. Eventualmente, havia a presença de pacientes que melhoraram com o tratamento e os pacientes difíceis eram atendidos por uma enfermeira, em sessões individuais. Parece haver influência de Pratt na proposta de grupos homogêneos (que reúnem pacientes com o mesmo sintoma) devido ao incentivo à presença de pacientes que obtiveram sucesso com o tratamento, como, por exemplo, os "Alcoólicos Anônimos" (Kaplan \& Sadock, 1983).

Em 1910, Moreno descreveu o uso da psicoterapia de grupo. Criou, em Viena, o "Teatro do Homem Espontâneo”, no qual veiculou o psicodrama e a representação de papéis, utilizando situações-problema para desenvolver a conscientização dos conflitos e propiciar sua resolução. O psicoterapeuta ("diretor") facilita ao paciente ("ator", "protagonista” ou "sujeito”) a expressão espontânea, por meio da dramatização de experiências passadas ou atuais, de ansiedades e expectativas futuras e mesmo de fantasias e sonhos, contando com a cooperação de outros profissionais ("egos auxiliares") ou dos membros do grupo ("plateia”). Ao final da representação, ela é comentada com o grupo, servindo de ajuda para o paciente e, também, para os demais participantes da ex- periência vivida. Em 1925, Moreno introduziu sua técnica nos Estados Unidos, e, no início dos anos 1930, propôs o termo "psicoterapia de grupo" para descrever tal tipo de prática. Representando papéis em vez de simplesmente falar, Moreno acreditava que os pacientes poderiam desenvolver sua espontaneidade e criatividade embotadas (Kadis et al., 1976; Rattner, 1977; Kaplan \& Sadock, 1983). Para Moreno, a psicoterapia de grupo seria uma nova cosmovisão, criando uma consciência cósmica, ao "libertar, já não o proletariado econômico, mas o terapêutico, isso é, todos aqueles que sofrem de deformações psíquicas" (Rattner, 1977, p. 23).

Ao se afastar de Freud, em 1912, Adler foi influenciado por alguns conceitos marxistas, especialmente o de "luta de classes", acreditando que o "interesse" ou "sentimento social" fosse a realidade mais básica da vida do ser humano, o que o levou a adotar um clima de igualdade, de abertura e de discussão livre em seus grupos. Tal postura, utilizada desde o final da primeira década do século XX, já prenunciava a atual psicoterapia de grupo (embora seus grupos não fossem terapêuticos), pois se propunha a indicar ao neurótico o "caminho para dentro da comunidade, (...) em ambiente social, a fim de que o maior número de pessoas pudesse dele aproveitar-se" (Rattner, 1977, p. 21).

Com um método semelhante ao de Pratt, Marsh foi, em 1919, o pioneiro na concepção do hospital como "comunidade terapêutica”, utilizando tratamento de grupo para pacientes mentais institucionalizados, grupos de discussão com o corpo técnico-hospitalar e alto-falantes para se comunicar com toda a população do hospital. Por volta dos anos 1920, Lazell tratava pacientes esquizofrênicos com o método de Pratt, sendo um dos primeiros a teorizar sobre o método de grupo, sugerindo que a socialização dos pacientes facilitava a mudança e criando associações de ex-pacientes (Kadis et al., 1976; Kaplan \& Sadock, 1983).

Em 1921, Freud publicou "Psicologia de Grupo e a Análise do Ego", dirigindo sua atenção para a psicologia coletiva:

(...) a psicologia de grupo interessa-se assim pelo indivíduo como membro de uma raça, de uma nação, de uma casta, de uma profissão, de uma instituição ou como parte de uma multidão de pessoas que se organizaram em grupo, numa ocasião determinada, para um intuito definido. (Freud, 1921/1976, p. 92. Grifo nosso)

Freud diferenciava o grupo sem líder (horda, turba ou massa), que é rebelde, capaz de excessos, ou mesmo perigoso, do grupo centrado em um líder, com o qual os membros se identificam e se relacionam com ele como um substituto parental e com os demais participantes como irmãos numa família, vivenciando, portanto, uma mutualidade de amor e de ódio (Kadis et al., 1976; Rattner, 1977; Kaplan \& Sadock, 1983). À semelhança de Trotter, 
seu contemporâneo, atribuía ao homem um instinto de rebanho, mas Freud não entendia tal predisposição humana como um instinto primário e indivisível, preferindo conceber o homem como criatura individual, incluída num grupo chefiado por um líder. Entretanto, o pai da psicanálise considerava a análise do papel do líder essencial para a compreensão do grupo. Consequentemente, tendia a crer que, sob liderança adequada, a "psicoterapia de grupo" - embora não fosse um termo utilizado por ele - pudesse propiciar alívio às doenças mentais (Kaplan \& Sadock, 1983).

No início dos anos 1920, nos Estados Unidos, Burrow introduziu o termo "análise grupal” ou "filoanálise”, convicto de que os indivíduos de uma mesma cultura sofrem de problemas psíquicos comuns. Discípulo de Freud e de Jung, não teve a aprovação de Freud à denominação de seu método; em 1933, foi-lhe negada participação na Associação Psicanalítica Americana, que havia fundado, mas, vários anos depois, recebeu dela grandes premiações. Burrow acreditava que o maior valor do grupo se devia à sua capacidade de diminuir as resistências do paciente ao tratamento, pois entrava em contato com outras pessoas que apresentavam problemas semelhantes, sendo encorajado a compartilhá-los e a criar com o grupo uma validação consensual, o que propiciaria maior conscientização psíquica. Organizou, ainda nos anos 1920, a primeira “comunidade terapêutica”, denominada de "Lifewynn" e situada nas montanhas Adirondack, de Nova York, consistindo num grupo em torno de vinte pessoas que viviam e trabalhavam juntas, num acampamento de verão. A influência de Burrow parece ter sido nítida no surgimento de outros centros de crescimento ligados ao chamado "movimento do potencial humano", no qual se insere a gestalt-terapia, de que tratarei mais adiante (Kadis et al., 1976; Rattner, 1977; Kaplan \& Sadock, 1983).

Na década de 1930, Bierer, discípulo de Adler, emigrado para a Inglaterra, reunia ex-pacientes psiquiátricos em “clubes sociais" e "comunidades terapêuticas", obtendo grande repercussão nesse país, o que levou à criação posterior de "hospitais diurnos e noturnos" para neuróticos e "casos fronteiriços" (Kadis et al., 1976; Rattner, 1977). Bierer buscava mais um "tratamento situacional" do que um conhecimento sobre o "subconsciente", visando a uma experiência concreta que levasse a uma mudança de atitude, fazendo o cliente abandonar seu papel de "objeto" e se assumir como "sujeito". Seus grupos se reuniam semanalmente com o psicoterapeuta para discutir problemas pessoais de forma impessoal; o psicoterapeuta, geralmente, adotava uma postura passiva e o grupo realizava atividades variadas (diversão, esportes, pintura e discussões). Podemos considerar como vantagens da terapia situacional de Bierer:

1) Eliminava o abismo entre percepção e cura que existe na psicanálise individual; (Isto se assemelha à filosofia de Burrow).
2) Os pacientes no hospital tornavam-se mais independentes, ativos e capazes de decidir por si próprios, o que apressava sua cura.

3) Tornava mais fácil para o paciente resolver problemas sociais que lhe criavam conflito no mundo exterior. (Kadis et al., 1976, p. 26)

Também nos anos 1930, Wender combinava, no hospital, psicoterapia de grupo com individual e o método de "aulas" e palestras com entrevistas terapêuticas. Trabalhando com doentes mentais brandos, se baseou em conceitos psicanalíticos, apesar de utilizar o método "educativo": o grupo era percebido como uma recriação da família e os pacientes como irmãos simbólicos; foram encontradas relações transferenciais entre os pacientes e o psicoterapeuta, e entre os pacientes, tendo o psicoterapeuta um papel central; também havia discussão e interpretação superficiais dos sonhos. Wender acreditava que os grupos aumentavam a espontaneidade do paciente, que favoreciam a exposição de material conflituoso nas sessões individuais e que, consequentemente, a tendência a se relacionar bem com outras pessoas era maior na psicoterapia de grupo do que na psicoterapia individual (Kadis et al., 1976; Kaplan \& Sadock, 1983).

Schilder, psiquiatra austríaco emigrado para os Estados Unidos na década de 1930-1940, também adotou uma combinação de psicoterapia individual e de grupo. Semelhantemente a Slavson e Klapman, utilizava procedimentos psicanalíticos mais rigorosos do que os de Wender, trabalhando em um hospital com pacientes neuróticos adultos, tanto internos quanto externos, formando grupos de quatro ou cinco participantes (Rattner, 1977; Kaplan \& Sadock, 1983). Schilder, Slavson e Klapman são os responsáveis pela introdução da interpretação ${ }^{2}$ psicanalítica na situação coletiva, pois trabalhavam com grupos homogêneos (em termos de enfermidade, sexo, idade, nível socioeconômico etc.), a partir da estrita seleção de seus membros, centrados num tema previamente proposto, o que facilitava com que as interpretações individuais servissem a todos. Tal fato permite a classificação da proposta de Schilder (bem como a de Slavson e a de Klapman) como uma “terapia interpretativa 'no' grupo" (Grinberg, Langer \& Rodrigué, 1957, p. 38). Schilder utilizava o conceito de "ideologia neurótica” (Rattner, 1977, p. 22):

(...) as ideologias dos pacientes se construíam em torno da imagem do eu ou do corpo e dela se desenvolviam. A psicoterapia permitia ao paciente ver que suas

\footnotetext{
2 Laplanche \& Pontalis. Vocabulário de Psicanálise. 6. ed. São Paulo: Martins Fontes, [s.d.]: "A) Destaque pela investigação analítica, do sentido latente existente nas palavras e nos comportamentos de um indivíduo. A interpretação traz à luz as modalidades do conflito defensivo e, em última análise, tem em vista o desejo que se formula em qualquer produção do inconsciente. B) No tratamento, comunicação feita ao indivíduo e procurando fazê-lo aceder a esse sentido latente, segundo regras determinadas pela direção e a evolução do tratamento" (p. 318-319).
} 
convicções tinham pouca base nos fatos. O paciente era forçado a perguntar a si próprio como chegara a aceitar determinada ideologia e como ela adquirira tanta influência sobre suas ações. Schilder acentuava que as idéias e convicções do paciente faziam parte de sua vida na comunidade e que era muito lógico discutir as ideologias de um paciente diante do grupo (...) A discussão começava em nível intelectual e conduzia às experiências da vida privada da pessoa. Este processo tirava o problema da esfera do indivíduo e atenuava o sentimento que o paciente tinha de estar isolado, quando outros pacientes eram capazes de identificar-se com ele e resolvê-lo. (...) O terapista de grupo precisa ter participação ativa com disposição de revelar sua própria ideologia e justificá-la perante o grupo. (Kadis et al., 1976, p. 25)

Em 1934, Slavson, originalmente um engenheiro, ao observar que a atividade espontânea de crianças em grupos recreativos produzia mudanças de comportamento, desenvolveu o "método ativo" na psicoterapia de grupo infantil, no qual o psicoterapeuta é permissivo e aceitador, proporcionando uma situação grupal especialmente planejada para a exposição dos conflitos. Apesar de sua formação, Slavson adotou o referencial psicanalítico, enfatizando mais o indivíduo do que o grupo como um todo e ampliando sua prática para incluir a psicoterapia de grupo com adolescentes e adultos (Kadis et al., 1976; Rattner, 1977; Kaplan \& Sadock, 1983).

É conceito de Slavson que os elementos comuns a todas as psicoterapias sólidas, incluindo a psicoterapia de grupo analítico, são os seguintes: (1) transferência; (2) catarse; (3) percepção ("insight”); (4) prova da realidade; e (5) sublimação ${ }^{3}$. É sua crença que a psicoterapia individual, embora contendo os três primeiros elementos, não contém os dois últimos como parte da situação de tratamento. A terapia de grupo, por outro lado, contém todos esses cinco elementos. Dentro da situação de grupo, vários tipos de relações podem levar ao apoio mútuo, a possível descarga de agressão ou ao abrandamento de sentimentos de culpa. (Kadis et al., 1976, p. 28)

Em 1948, Slavson fundou a Associação Americana de Psicoterapia de Grupo. Slavson (1953), bem como Grinberg, Langer e Rodrigué (1957) descreveram uma série de trabalhos de outros profissionais anteriores e contemporâneos deles: Green trabalhava com grupos de gagos, já em 1920; Buck, em 1937, utilizava um método semelhante ao de Pratt com pacientes hipertensos, enquanto Chappel, Stefano, Rogerson e Pike aplicaram o

\footnotetext{
Para melhor elucidação destes termos, consultar Laplanche \& Pontalis ([s.d.], p. 95-97, 135-141, 490-495, 637-641 e 668-678) e Cabral \& Nick. Dicionário Técnico de Psicologia. São Paulo: Cultrix (1974, p. 54, 190, 198, 285, 329, 371 e 386).
}

mesmo método em pacientes com úlcera gástrica; Hadden, em 1942, fez o mesmo com tuberculosos, diabéticos, neuro-sifilíticos e pacientes sem problemas orgânicos; Altschuler incluiu a atividade artística em sua proposta; Weininger, nos anos 1940, trabalhou com uma clientela privada, mas sem publicar suas conclusões, numa atitude semelhante à de Wolf, que fazia tratamento individual no grupo, tendo originado a sessão alternada (encontros sem a presença do psicoterapeuta).

Embora não tenha sido psicoterapeuta, mas psicólogo social, Lewin (1978), juntamente com Lippit e White, pesquisou as relações entre vida grupal e liderança, enfocando a "dinâmica de grupo", termo criado por ele em 1939 (Rattner, 1977; Kaplan \& Sadock, 1983):

(...) a tendência na psicoterapia de grupo foi estudar o indivíduo dentro do grupo. Embora tentativas tenham sido feitas de examinar como o grupo como uma totalidade funcionava, o grupo era, como o colocava Freud, simplesmente uma coleção de indivíduos reunidos juntos para um objetivo particular. Foi o movimento da psicologia social, encabeçado por homens como Kurt Lewin, que viu o grupo como diferente qualitativamente da simples soma de suas partes. De acordo com Lewin, o grupo é uma entidade em seu próprio direito, com qualidades particulares e únicas que são diferentes dos indivíduos dos quais é composto (...) Para Lewin, os atos do indivíduo não podem ser explicados sobre a base de uma psicodinâmica do indivíduo, mas devem ser explicados sobre a base da natureza das forças sociais, o campo, ao qual está exposto. (Kaplan \& Sadock, 1983, p. 4)

Representando uma nova versão da psicologia gestaltista, Lewin (1978) compreendeu que a pressão grupal influenciava os membros de um grupo no sentido de alterar seu comportamento, e eles, por sua vez, influenciam o grupo, formando uma "gestalt" ou totalidade, composta de elementos heterogêneos, mas funcionando como unidade. Rattner (1977) afirma que

Lewin e seus colaboradores puderam provar que dos três estilos de liderança experimentalmente examinados ("autocrático", "democrático" e "laissez faire”) somente o princípio democrático de liderança promovia nos sujeitos do experimento, espontaneidade e capacidade de colaborar. (p. 25)

Sob a influência de Lewin (1978) e de outros psicólogos sociais, foram fundados, em 1947, os "National Training Laboratories" (NTL), que desenvolveram o "grupo-T" ("grupo de treinamento"), visando a enriquecer o processo educacional. Tal tipo de grupo, geralmente composto de pessoas psicologicamente saudáveis, foi chamado de 
(...) "terapia para normais", (...) mas pessoas perturbadas freqüentemente encontram seu caminho no grupo-T para o tratamento de desordens mentais, em vez de nas formas tradicionais de psicoterapia. $\mathrm{O}$ grupo-T atrai especialmente aquelas pessoas que se sentem isoladas e alienadas, que têm dificuldade de se relacionar com outras pessoas e com falta de auto-determinação. (Kaplan \& Sadock, 1983, p. 5)

Durante a II Guerra Mundial, Foulkes (1976) empregou suas técnicas psicoterápicas grupais a serviço das forças armadas britânicas. Trabalhando com grupos selecionados por faixa etária e nível de inteligência, buscou fazer uma "ponte" entre a vida passada do paciente e o "aqui-e-agora" situacional. Utilizando o referencial psicanalítico, descreveu a situação transferencial dos membros do grupo em relação ao psicoterapeuta, entre os membros grupais e, também, deles em relação ao grupo como totalidade (Kadis et al., 1976; Kaplan \& Sadock, 1983). Para ele, a psicoterapia de grupo seria "um novo campo de interação no qual cada indivíduo tem um novo começo" (Foulkes, 1976, p. 17), numa situação imparcial, diferente da familiar, podendo se comparar com outros modos de ser, de agir e de perceber, ou seja, "um instrumento, tensa entre o talvez o primeiro adequado, para a focalização prática do problema-chave de nosso tempo: a relação indivíduo e a comunidade" (p. 26).

Por sua vez, Grinberg, Langer \& Rodrigué (1957) propuseram, ainda sob o referencial psicanalítico, a técnica interpretativa no grupo, que tomava não mais apenas o indivíduo como fenômeno central e ponto de partida de toda interpretação, lidando com a totalidade das manifestações do grupo e transcendendo os seus elementos (pacientes). Inicialmente na Inglaterra, e, posteriormente, nos Estados Unidos, Bion (1975) publicou, em 1961, "Experiências com Grupos", no qual, partindo de observações feitas em grupos militares, as aplicou à psicoterapia de grupo. Concebendo o grupo como totalidade, Bion se referia a três atitudes ou princípios básicos na formação de grupos, que podem agir simultaneamente e em intensidade variável:

- dependência: os membros do grupo buscam um líder que lhes proporcione apoio e proteção espiritual;

- formação de pares: eventualmente, os participantes do grupo reconhecem a existência do líder apenas em fantasia, a irracionalidade da expectativa de ajuda de uma figura onipotente e onisciente e a necessidade de buscar em si mesmos sua salvação e sua sobrevivência, o que lhes leva à formação de grupos de pares;

- luta e fuga: compreendendo a inexistência de tal líder, os membros do grupo se sentem incomodados e desapontados. Alguns reagem brigando entre si ou com o líder; outros abandonam a situação de grupo por considerarem-na insuportável. O papel do líder seria interpretar, oportunamente, a ocorrências das atitudes descritas acima, facilitando a obtenção de um funcionamento maduro do grupo, no qual seus membros sejam responsáveis por suas decisões e ações (Kaplan \& Sadock, 1983).

Em 1962, foi fundada, na Califórnia (EUA), a comunidade de Esalen, que se tornou um importante centro de crescimento e influenciou a formação de outros centros. Integra, até hoje, psicologia, filosofia e meditação oriental, além de outras práticas. Fritz Perls, o criador da gestalt-terapia, ali viveu, no período de 1964 a 1969 (Kaplan \& Sadock, 1983). Surpreendentemente esquecido pela maioria dos historiadores da psicoterapia de grupo, não poderia deixar de citar Rogers (1970), o criador dos "grupos de encontro", que influenciou a atuação de psicoterapeutas grupais de vários referenciais, principalmente os humanistas e, entre eles, os gestalt-terapeutas. Rogers definia o "grupo de encontro" como aquele que "pretende acentuar o crescimento pessoal e o desenvolvimento e aperfeiçoamento da comunicação e relações interpessoais, através de um processo experiencial” (p. 14), acrescentando que "os grupos de encontro conduzem a uma maior independência pessoal, a menos sentimentos escondidos, maior interesse em inovar, maior oposição à rigidez institucional (...). Eles produzem a mudança construtiva” (p. 23). Rogers atribuía o nascimento e o desenvolvimento de tal tipo de grupo a certa marginalidade em relação às instituições sociais, levando à criação de um movimento baseado nos referenciais da psicologia gestáltica (principalmente Lewin) e da abordagem centrada na pessoa, desenvolvida pelo próprio Rogers. Acreditava que tais grupos eram procurados devido à crescente desumanização da cultura ocidental e, por outro lado, a uma busca de satisfação de necessidades psicológicas. Podese destacar a contribuição rogeriana às práticas grupais com sua compreensão de que o grupo

(...) é semelhante a um organismo, possuindo o sentido de sua própria direção (...) (p. 52), [de que] os grupos de encontro só podem florescer num ambiente essencialmente democrático (p. 154), [sendo] uma tentativa para enfrentar e superar o isolamento e alienação do indivíduo na vida contemporânea. (p. 156)

Assim, posso, neste ponto, discutir a evolução da psicoterapia de grupo desde Pratt até aos tempos atuais: Grinberg, Langer \& Rodrigué (1957) denominaram a forma de trabalho em grupo de Pratt e de seus primeiros seguidores (que tratavam, principalmente, de pacientes com distúrbios orgânicos) de "terapias exortativas paternais que atuam 'pelo' grupo" (p. 32-33), pois estimulavam e utilizavam as emoções vividas nos grupos, sem buscar compreendê-las, se centrando na figura "paternal" do psicoterapeuta. Afirmavam que tal forma de psicoterapia suscitou o surgimento de psicoterapias "que atuam 'pelo' grupo com estrutura fraternal” (p. 33), citando, como exemplos, o psicodrama moreniano, bem como os trabalhos de Marsh, Wender, Low \& Lazell, que adota- 
vam um dinamismo parecido com as "terapias exortativas paternais", mas propiciavam uma fraternidade e uma homogeneização dos componentes do grupo, o que restringia a influência do líder. A partir da incorporação da interpretação psicanalítica aos grupos de psicoterapia (com Slavson, Schilder e Klapman) e a formação de grupos homogêneos (na sintomatologia, no sexo, na condição socioeconômica, na idade etc.), os psicoterapeutas passaram, cada vez mais, a fazer "terapia interpretativa individual 'no' grupo” (p. 38), que utilizava interpretações individuais, mas comuns a todos os membros do grupo:

(...) é relativamente recente o intento de tratar o grupo como uma totalidade, ou unidade dinâmica; quer dizer que data de pouco tempo a chamada psicoterapia "do" grupo. Como a partícula "do" o sugere, esta concepção terapêutica se interessa pelo núcleo em si mesmo, fazendo do fenômeno grupal seu campo de investigação e de possíveis operações terapêuticas. (Grinberg, Langer \& Rodrigué, 1959, p. 6-7)

Como podemos perceber, as primeiras experiências de psicoterapia de grupo (Pratt e seus seguidores) concebiam o grupo como "massa", necessitando da intervenção e da exortação de um "patriarca" que o conduzisse "pelo" manancial de suas emoções confusas. Posteriormente, surgiram práticas que se isentavam da intervenção sistemática do psicoterapeuta, buscando a homogeneidade do grupo, quer concebessem seus membros como "irmãos", quer como indivíduos diferenciados entre si. Finalmente, cada vez mais, foi sendo minimizada - embora não de forma generalizada - a concepção meramente "individualista”, os líderes considerando a perspectiva "grupal” como abrangedora dos aspectos intrapsíquicos, interpessoais e do grupo propriamente dito e as repercussões socioculturais do meio no qual ele está inserido.

Outra conclusão a que posso destacar a partir da história da psicoterapia de grupo diz respeito aos seus aspectos "psicopedagógicos"4. Pratt iniciou uma abordagem eminentemente "didática”, adotada por vários profissionais que o seguiram ao longo dos anos, mas sua atuação era essencialmente "exortativa”, quando não "repressiva” (Zimmermann, 1971). Com a introdução da psicanálise nas práticas grupais e a consequente compreensão do grupo como uma espécie de família, a perspectiva "psicopedagógico-familiar" se ampliou, indo além da interpretação do indivíduo isolado para incluir interpretações das relações interpessoais: entre os pacientes (relação "filho"-“filho”), entre o paciente e o psicotera-

\footnotetext{
São inegáveis as diferenças entre psicoterapia (grupal ou individual) e pedagogia. Enquanto a primeira se centra em questões emocionais e, apenas secundariamente, em questões intelectuais e informativas, a segunda parece priorizar as mesmas questões de forma inversa. Entretanto, acredito que ambas as atividades visam à aprendizagem: na pedagogia, de conhecimentos e de habilidades, geralmente formais, e, na psicoterapia, de atitudes e de comportamentos suscitados por experiências significativas da vida das pessoas.
}

peuta (relação "filho"-"pai”), entre o paciente e o grupo (relação "filho"-“mãe”) e entre o psicoterapeuta e o grupo (relação "pai”-“mãe”). Entretanto, é a partir daqueles que influenciaram as psicoterapias grupais humanistas, como Moreno (com o "teatro da espontaneidade"), Adler (a partir do "interesse" ou "sentimento social"), Burrow e Bierer (a criação de "comunidades terapêuticas" e a ênfase no "tratamento situacional”), Lewin (a "dinâmica de grupo" e a noção de "campo") e Rogers (os "grupos de encontro"), que penso que a perspectiva da psicoterapia de grupo como uma psicopedagogia da vida ${ }^{5}$ atingiu seu grau máximo, criando possibilidades e recursos múltiplos para a facilitação da resolução de conflitos, não apenas intrapsíquicos, mas, também, relacionais e grupais, a partir do contexto real em que os participantes do grupo estão inseridos, indo além das suas possíveis representações ideais ou simbólicas. Sendo mais claro: tal psicopedagogia da vida inclui todas essas "realidades", considerando-as pertinentes à "gestalt” ou à totalidade que se configura no "aqui-e-agora" do grupo.

A passagem da perspectiva individual "pelo" ou "no" grupo à perspectiva "do" grupo também faz parte da evolução histórica da psicoterapia de grupo em gestalt-terapia, como abordarei a seguir.

\section{Considerações finais}

Além de suas propostas e elaborações dentro da perspectiva psicanalítica, Grinberg, Langer \& Rodrigué (1957; 1959) classificam as várias propostas de trabalho grupal:

- terapias exortativas paternais que atuam "pelo" grupo: incluem a proposta de Pratt e de seus primeiros seguidores, que estimulavam e utilizavam as emoções grupais, sem objetivo de compreensão, centrando-se na figura "paternal" do psicoterapeuta;

- terapias exortativas que atuam "pelo" grupo com estrutura fraternal: incluem a propostas de Moreno, Marsh, Wender e Lazell, de dinamismo semelhante às citadas acima, mas restringem a influência do líder grupal através da homogeneização dos participantes, propiciando uma vivência fraternal;

- terapias individuais "no" grupo: surgidas principalmente com a incorporação da interpretação psicanalítica, como em Slavson, Schilder e Klapman, buscam formar grupos homogêneos, analisando os conteúdos comuns aos vários membros grupais;

\footnotetext{
Observe-se que, apesar do termo psicopedagogia da vida ser pouco preciso e excessivamente abrangente, visa a destacar os necessários vínculos entre a vivência grupal e as relações sociais, compreendendo o espaço do grupo como meio de articulação e de mediação da aprendizagem pessoal, interpessoal e coletiva, bem como da conscientização da reprodução das relações sociais de dominação que se manifestam de forma mascarada no contexto do grupo. Portanto, tal perspectiva requer que se leve em conta o poder das pessoas, de suas relações e de suas formas de organização como meios de interferência, resistência, pressão e ação sobre a sociedade, além da consideração de como o grupo sofre a influência da sociedade.
} 
- terapias "do" grupo: abordagens mais recentes, que tratam o grupo como totalidade dinâmica, tendo o fenômeno grupal como campo de investigação e de possíveis intervenções psicoterápicas em seus níveis intrapsíquico, relacional e grupal, além de refletirem as repercussões sócio-culturais sofridas pelo grupo do meio em que está inserido.

A história da psicoterapia de grupo revela também uma evolução quanto aos seus aspectos sócio-pedagógicos. As primeiras propostas de psicoterapia grupal eram eminentemente didáticas e exortativas, quando não repressivas. A inclusão da perspectiva psicanalítica na psicoterapia de grupo permite uma ampliação do enfoque sobre o indivíduo isolado para uma perspectiva interpessoal, mais precisamente uma ênfase aos aspectos pedagógico-familiares: o grupo como uma "família". O advento de propostas várias, como as de Moreno (teatro da espontaneidade e representação de papéis psicodramáticos), Adler (interesse social), Burrow e Bierer (comunidades terapêuticas e tratamentos situacionais), Lewin (dinâmica de grupo e noção de campo) e Rogers (grupos de encontro), criou um vasto campo de atuação no que se refere às práticas grupais, especialmente entre as psicoterapias humanistas, que podemos caracterizar como uma psicopedagogia da vida, voltada para a utilização dos vários recursos disponíveis não só para as vivências pessoais, interpessoais e grupais, mas indo além das possíveis representações simbólicas e ideais; ou seja, tratando do contexto real em que estes grupos estão inseridos, suscitando não só a conscientização da reprodução das relações sociais de dominação no contexto grupal, como também o reconhecimento do poder de interferência, resistência, influência e ação do grupo sobre a sociedade.

É nesta última perspectiva que podemos incluir a gestalt-terapia, apesar de alguns limites quanto às suas iniciativas grupais, pelo menos na prática de seu criador, Frederick Perls, e de alguns de seus seguidores. Psiquiatra de origem judaico-alemã, Perls era um espírito irrequieto e instigante. Enfrentou os horrores das duas grandes guerras mundiais, o "apartheid" sul-africano e a reativação do fascismo nos Estados Unidos, no final dos anos sessenta. De formação psicanalítica, incorporou, através de sua própria experiência, uma série de influências, que vão desde o teatro expressionista ao zen-budismo, passando pela análise do caráter e as "viagens" alucinógenas. Perls, que se considerava um psicanalista medíocre, criou uma abordagem viva que, hoje, integra o rol dos referenciais psicológicos mais reconhecidos.

\section{Referências}

Bion, W. R. (1975). Experiências com grupos: os fundamentos da psicoterapia de Grupo. São Paulo/Rio de Janeiro: EDUSP/Imago.
Cabral, A. \& Nick, E. (1974). Dicionário Técnico de Psicologia. São Paulo: Cultrix.

Fonseca, A. H. L. da. (1988). Grupo: fugacidade, ritmo e forma. Processo de grupo e facilitação na psicologia humanista. São Paulo: Ágora.

Foulkes, S. H. (1976). Psicoterapia e psicoterapia de grupo. In: Kadis, A. L., Krasner, J. D., Winick, C. \& Foulkes, S. H. Psicoterapia de grupo (p. 11-21).São Paulo: IBRASA.

Freud, S. (1976). Psicologia de grupo e a análise do ego. In: Edição standard brasileira das obras psicológicas completas de Sigmund Freud. Rio de Janeiro: Imago (Original publicado em 1921).

Grinberg, L., Langer, M. \& Rodrigué, E. (1957). Psicoterapia del grupo: su enfoque psicoanalítico. Buenos Aires: Paidós.

Grinberg, L., Langer, M. \& Rodrigué, E. (1959). El grupo psicológico en la terapéutica, enseñanza y investigación. Buenos Aires: Nova.

Kadis, A. L., Krasner, J. D., Winick, C. \& Foulkes, S. H. (1976). Psicoterapia de grupo. São Paulo: IBRASA.

Kaplan, H. I. \& Sadock, B. S (1983). Comprehensive group psychotherapy. Baltimore: Williams \& Williams.

Laplanche, J. \& Pontalis, J.-B. Vocabulário da psicanálise. 6. ed. São Paulo: Martins Fontes, [s.d.].

Lewin, K. (1978). Problemas de dinâmica de grupo. São Paulo: Cultrix.

Rattner, J. (1977). Terapia de grupo: a psicoterapia do futuro. Petrópolis: Vozes.

Rogers, C. R. (1970). Grupos de encontro. São Paulo: Martins Fontes.

Slavson, S. R. (1953). Psychothérapie analythique de groupe: enfants, adolescents, adultes. Paris: Presses Universitaires de France.

Zimmermann, D. (1971). Estudos sobre psicoterapia analítica de grupo. São Paulo: Mestre Jou.

Georges Daniel Janja Bloc Boris - Psicólogo, mestre em educação e doutor em sociologia pela Universidade Federal do Ceará. Professor titular do Programa de Pós-Graduação em Psicologia da Universidade de Fortaleza. Coordenador do APHETO - Laboratório de Psicopatologia e Psicoterapia Humanista-Fenomenológica Crítica. Tradutor para o português do primeiro livro de Fritz Perls, Ego, Fome e Agressão: Uma Revisão da Teoria e do Método de Freud. Psicoterapeuta, supervisor de estágio em psicologia clínica e formador de psicoterapeutas em Gestalt-Terapia. Autor de Falas de Homens: A Construção da Subjetividade Masculina e de Grupos Vivenciais e Cooperação: Uma Perspectiva Gestáltica.E-mail: geoboris@uol.com.br 